\title{
THE STORY OF MOUTH HYGIENE IN DETROIT.
}

\author{
By George F. Burke, D. D.S., Detroit, Mich.
}

(Read before the National Dental Association at Its Twenty-second Annual Session, Chicago, Ill., August 5-9, 1918.)

$\mathrm{T}$

HAT great scientist, Dr. G. V. Black, to whose memory a splendid monument will be unveiled at this meeting, once said: "I am very decidedly of the opinion that if our children could be taught to take proper personal care of their own teeth, that teaching would do more good than all the doctors in Christenden."

Richard Henry Grady, the brilliant editor of the Atlantic Constitution, proclaimed on a certain occasion that "John Barleycorn was doing more harm to the human race than all the wars, famines, and pestilences combined." A few decades later Dr. Osler stated that defective teeth were causing more physical deterioration than Barleycorn.

If the foregoing statements are true, man's worst enemy is his neglected mouth, and it should be said in defense of these spokesmen that their statements have never been questioned by scientific men. Few of us who only regard ourselves as reasonably well initiated have a right appreciation of the hidden horrors that lurk in diseased mouths, but we are awakening to a somewhat startled realization of the overwhelming importance to our welfare of clean, well cared for mouths.

I need not plead the cause of mouth hygiene before this gathering. My story will tell you how Detroit is dealing with this problem. Detroit was one of the first cities in the United States to provide for the dental care of its school children. My story will be valuable only in so far as I shall be enabled out of my experience in Detroit, to point the way, to some extent at least, to others who are anxious: to do a similar service in their communities.

In any effort to secure funds for mouth hygiene work by public appropriation it is well to bear in mind that you will have opposed to you, that very large class of our citizenship who everlastingly have their minds centered on a low tax rate. The merits of this propaganda must be very clearly put before these people before they will accept your teachings. Altruism or a spirit to sacrifice will avail little if the propagandists are not shrewd, and diplomatic. Especially is this true, if your cause is, or seems to be a new one. To the great mass of human beings, mouth hygiene is still a new doctrine. Proof of this is shown in the fact that sixty per cent of the mouths of the men in the new national army are in a deplorable condition.

In order to make progress and give impetus to this movement in Detroit we circulated five hundred petitions addressed to the citizens. These were care fully worded, and brief, and resulted in our securing twenty thousand signatures of residents, many of whom were leaders among the business and professional classes of the city.

Prominent merchants and clergy men apparently were pleased when asked to head these petitions with their own signatures. It proved to be a form of flattery, which apparently was very much to their liking. Later these petitions were taken to the managing editor of the different newspapers and the effect 
was magical. They saw there not only the names of the city's merchant princes, and medical men, but the leaders in the churches. They responded as a unit in giving our effort not only editorial support, but furnished news items in quantity.

There is always much criticism of the press, just as there is of the pulpit. How justifiable it is, I am not in a position to know, but it seems to me that there is no power so overwhelming, so far-reaching, swift and penetrating as the power of the press. The papers reach the people all the time and to them should be given a large share of the credit for the success of our movement in Detroit.

It seems needless for me to bore you with details. To be brief, an appropriation of five thousand dollars was allowed when this work was first started some half dozen years ago, and there has been allowed for the school year of 1918-19 the sum of twenty-five thousand dollars, which funds will be expended for clinics located in the poorer districts, general inspection of the children's mouths in both the parochial and public schools, and lecture work given to teachers and pupils, by dentists.

It was with the hope of bettering the dental conditions of all classes of school children that Detroit adopted its present method of caring for their dental ailments. One very noticeable feature of our work is the added knowledge which parents have in regard to the first permanent molars. To this pardonable lack of knowledge on the part of parents is due, I believe to a very great extent, much of the dental suffering; and had mouth hygiene accomplished no other results the undertaking has been a success, for thru it, parents and children are being educated to the full value of the first permanent molar. Not alone have these children been benefited because of dental treatment, but they have been taught much of the value of clean, well cared for teeth. Missing incisor teeth and green stains, so frequently found in children's mouths, are not so common in Detroit, the children are taking a greater pride in their personal appearance.

A study of the official reports of the work done in the clinics reveals the very interesting fact that, since this work was first undertaken, the number of children applying for treatment of Odontalgia have steadily declined in a very marked degree. Does this not show that this work has been effective?

A very potent influence for inducing children to take better care of their teeth is a system of grading or marking the children on mouth hygiene on their monthly report cards. The children are marked " $S$ " or " $U$ " for unsatisfactory on the monthly report card which goes to the home for the signature of parents or guardian.

For a child to bring a report card home showing mouth hygiene marked "U" seems to injure the pride of not alone the child, but the parents, resulting in a desire to improve the mouth condition so that the " $U$ " will be changed to an "S". For some parents to send their children to school with foul, filthy, ill-smelling mouths, is not fair to the other children; therefore it is well that thru this system of marking the facts can be made known at home so that these conditions can be corrected.

Ardent followers in this work frequently complain because this movement does not spread with greater rapidity. Education is not a rapid process; the world grows better slowly. But to these who cry out because of the lack of interest in this particular field of hygiene, it is well to call their attention to a most significant sign. I refer to the industrial clinic. Many corporations have recently added the dental clinic to care for the mouths and teeth of their employees.

Big Business has for some time been back of the dry movement in this country, for the reason that a sober workman is a better worker than a 
drunkard. Big Business is now learning that employees are more efficient with healthy mouths and teeth than they are with a diseased, impaired masticating apparatus. What these signs point to no sane person will question, and no doubt the industrial dental clinic will grow by leaps and bounds during the next decade. The very wide avenues thrown open from the stand point of education by means of the industrial dental clinic must be apparent to all thoughtful students of this subject.

Such men and women as Fones of Bridgeport, Forsythe of Boston, Ebersole of Cleveland, Oakman and Griffen of Detroit; Eastman, Belcher, and Burkhart of Rochester, and Maude Tanner of Portland, Oregon, have been a tower of strength in this movement for healthier mouths, and let us hope that their good work will be well carried on.

It isn't always an easy matter to start the ball rolling, to overcome the apathy inherent in so large a proportion of the people of all classes; but the fight is tremendously worth while, and if professional jealousies and petty, befogging issues can be forgotton and cooperation among the dentists achieved the struggle is not half so hard and the results far quicker and more splendid.

\section{Discussion.}

\section{Charles H. Oakman, Detroit, Mich.}

I knew that Doctor Burke's paper would be very interesting and would furnish food for thought. Having been associated with Doctor Burke in Oral Hygiene for a number of years, I knew that he was well qualified to write on this subject. For a number of years, I have been frequently asked, "How can we take up Oral Hygiene in the community in which we live?" This is a very pertinent question. I believe that if the profession as a whole were to answer this question, there would be a great many differences of opinion on this subject. As doctor Burke has stated, if we had gone to the managing editors of the daily press and asked for editorials stating what Oral Hygiene stood for, no doubt, they would scarcely have given us an audience. Instead, we went to the voters and secured twenty thousand signatures, so when the editors asked what the idea was, we stated that these twenty thousand people believed that the teeth of the children in the public and parochial schools should be cared for by the city. Many of those who had signed had been the victims of poor teeth most of their lives. It struck them as a humanitarian as well as a health measure, so when the editors asked us on what we had to substantiate our claim, we presented these lists of names at the same time stating that they were building in Boston, the Forsyth Dental Infirmary, the building costing nearly a million dollars and millions for endowment. After receiving this information, a wire was immediately sent to their newspaper representative in Boston asking for detailed information regarding the Forsyth Dental Infirmary.

When the reply came, it took up several columns in one of the daily papers. It was only a few days before all the papers were giving liberally of space as well as editorials on the benefits of Oral Hygiene in the schools. We did not stop at one or two papers but we saw the editors of every daily and weekly paper published in Detroit.

I hope the time is not far distant when every city will have annual appropriations for Oral Hygiene. The money should be raised by taxation and can come either thru the health or school board budget. While Oral Hygiene is thriving in certain parts of the country, there are still cities of large size where the work is not progressing like it should. However, I am not adverse to endowments, for some of the greatest institutions in the world are endowed institutions, such as the Forsyth and Rochester Dental Infirmaries.

The credits given children for Oral Hygiene have been a wonderful factor 
in this work, for a child who continues to receive a poor mark in Oral Hygiene is looked upon by the other children as an undesirable citizen. The lecturers in the schools inform the children that if they neglect their mouths, they not only harm themselves but contaminate those who breathe the same atmosphere. On their monthly report card, Oral Hygiene appears as prominent as does the three "R's."

In regard to work of the hygienist, no one can operate in the mouth who is not a registered dentist. In order that the hygienist may practice in Michigan, it would be necessary to have special legislation. This work could be tried out in the public schools and hospitals.

How many full time operators have you?

We have twenty operators about onehalf of whom are full-time men.

In regards to operators, what do you think are the best, full time or half time operators, that is, men who are practicing half the time or men devoting all their time to this work?

'The trouble in dentistry thruout the country is that there are not enough dentists. This, of course, is more marked since United States entered the war. We find it difficult to secure enough dentists. If it were possible, I think it would be better to have full-time men. We have engaged some very good men; some who have come to Detroit to live, and while their practice is being built up, they could easily give half of their time to the clinics. Personally, I believe that recent graduates' salary should not exceed one thousand dollars per year. As a rule, they have had little experience in practice, and the clinic to them is really post-graduate work. The mistakes they make in the clinics are left behind and will not follow them as they would if they were in private practice. If we could get good men with big experience, three thousand dollars would not be paying them any too well. Men in smaller cities who are supervis- ing the work in the schools and who have executive ability, should even receive greater compensation because much of their work is done at night, and outside of regular hours. The question has often come up as to whether central or auxiliary clinics are the best. In any large city with the population approaching a million, I am of the opinion that it would be well to have both central and auxiliary clinics. In this way, it saves the child going a long distance on the cars and getting home in the dark. If the clinics were in the schools or near their homes, they can easily go unattended, at the same time not having the expense of carfare for the mother and children, and this is often a big item to poor people. It is difficult for one to outline this policy for certain cities without knowing the manner in which the city is laid out. I believe the time is near at hand when this question can be settled. As to the salary of the dental nurse, in Detroit, we pay them $\$ 50.00$ per month. As a rule, they have not had much experience. However, when they become proficient, I believe their salaries should be increased. Dr. Raugh asked the relationship between Oral Hygiene Committee and the $\mathrm{Mu}$ nicipal Committee. Where there are dentists on the boards of health or school boards, if they have full control of the work, they can spend the money as they see fit, but it is always advisable to work in harmony with the district society. Suggestions can often be given which would be of value. If there is dissension in the dental society, with the one who is supervising the work, it is only a question of time the work is bound to be disrupted. I believe a dentist should be on the board of health or school board providing he is qualified and has interests of the Oral Hygiene at heart. If he is a member of these boards more for political purposes than for the good he can do for the cause of Orai Hygiene, it is better that he were never appointed. 